\title{
Considerations Regarding Age at Surgery and Fistula Incidence Using One- and Two-stage Closure for Cleft Palate
}

\author{
Stoicescu Simona1,2, Enescu DM11,2 \\ ${ }^{1}$ Plastic and Reconstructive Surgery Chair, "Grigore Alexandrescu" Emergency Clinical Hospital for Children, Faculty of Medicine, "Carol Davila" University of \\ Medicine and Pharmacy, Bucharest, Romania \\ 2 Clinic of Plastic Surgery, Reconstructive Microsurgery and Burns, "Grigore Alexandrescu" Emergency Clinical Hospital for Children, Bucharest, Romania
}

\begin{abstract}
Introduction: Although cleft lip and palate (CLP) is one of the most common congenital malformations, occurring in 1 in 700 live births, there is still no generally accepted treatment protocol. Numerous surgical techniques have been described for cleft palate repair; these techniques can be divided into one-stage (one operation) cleft palate repair and two-stage cleft palate closure. The aim of this study is to present our cleft palate team experience in using the two-stage cleft palate closure and the clinical outcomes in terms of oronasal fistula rate.

Material and methods: A retrospective analysis was performed on medical records of 80 patients who underwent palate repair over a five-year period, from 2008 to 2012. All cleft palate patients were incorporated. Information on patient's gender, cleft type, age at repair, one- or two-stage cleft palate repair were collected and analyzed.

Results: Fifty-three (66\%) and twenty-seven (34\%) patients underwent two-stage and one-stage repair, respectively. According to Veau classification, more than $60 \%$ of them were Veau III and IV, associating cleft lip to cleft palate. Fistula occurred in $34 \%$ of the two-stage repairs versus $7 \%$ of one-stage repairs, with an overall incidence of $24 \%$.

Conclusions: Our study has shown that a two-stage cleft palate closure has a higher rate of fistula formation when compared with the one-stage repair. Two-stage repair is the protocol of choice in wide complete cleft lip and palate cases, while one-stage procedure is a good option for cleft palate alone, or some specific cleft lip and palate cases (narrow cleft palate, older age at surgery).
\end{abstract}

Keywords: cleft palate, two-stage closure, palate fistula, Veau classification

Received: 15 July 2013

\section{Introduction}

There is a universal controversy in the literature regarding the best surgical technique and the optimal timing for the closure of cleft palate, with many treatment protocols, but none generally accepted.

There are mainly two approaches for cleft palate repair. Considering the number of stages for closure, the cleft palate can be repaired using one-stage or two-stage protocols. One-stage closure of both the hard and the soft palate is considered the classical approach, widely used in the United States $[1,2]$, and there are described various operative techniques: the von Langenbeck, the Veau-Wardill-Kilner, the Bardach two-flap palatoplasty or vomer flap for hard palate repair, either of these together with Sommerlad's intravelar veloplasty or Furlow double-opposing Z-plasty for correct soft palate repair [3].

Two-stage cleft palate repair refers to soft and hard palate closure in two different stages, generally soft palate earlier for good speech result and hard palate later for allowing superior maxillary development [4]. This protocol, also called the delayed hard palate closure or Schweckendiek protocol is used mainly in Europe, especially according to the Eurocleft report [5]; the Eurocleft intercenter study

Correspondence to: Simona Stoicescu

E-mail: simona_ioana@hotmail.com demonstrates better outcome in terms of maxillary growth with the delayed hard palate repair compared with the classical protocol [6]. For this reason, our cleft palate team followed this protocol for over a decade.

The aim of this study is to present our experience in using the two-stage cleft palate closure, its benefits and also its limits, especially regarding the higher incidence of palate fistula formation.

\section{Material and methods}

A retrospective analysis was done on our cleft lip and palate database based on medical records; we selected all children treated by primary cleft palate repair during the last 5 years, between January 1st, 2008 and December 31 3012 by our cleft palate team. Children treated for primary cleft lip repair or for secondary procedures (lip revision, rhinoplasty, palatal fistulas, alveolar bone graft, velopharyngeal insufficiency, etc) were excluded.

The following data were recorded: patient's gender, date of birth, type of cleft, age of the first stage cleft palate repair, age of the second stage cleft palate repair (if applicable), surgical technique used, bleeding and blood transfusion during surgery (if necessary), information about the presence of any oronasal fistulae.

Cleft type was categorized according to the Veau classification: Veau I (soft cleft palate), Veau II (hard and soft cleft 
Table I. Gender versus cleft type representation

\begin{tabular}{lcclc}
\hline Cleft type & Girls (\%) & Boys (\%) & Total $\mathrm{n}=80$ & \\
\hline Veau I & 6 & 5 & $\mathrm{n} 1=11(13.75 \%)$ & $\begin{array}{c}31 \text { isolated cleft } \\
\text { palate (CP) }\end{array}$ \\
Veau II & 11 & 9 & $\mathrm{n} 2=20(25 \%)$ & $\begin{array}{c}\text { cleft lip and } \\
\text { Veau III }\end{array}$ \\
Veau IV & 3 & 30 & $\mathrm{n} 3=33(41.25 \%)$ & palate (CLP) \\
Total & $23(28.75 \%)$ & $57(71.25 \%)$ & $\mathrm{n} 4=16(20 \%)$ & \\
\hline
\end{tabular}

Table II. Relation between cleft type and age of palate closure

\begin{tabular}{|c|c|c|c|c|c|}
\hline \multirow{2}{*}{$\begin{array}{l}\text { Cleft } \\
\text { type }\end{array}$} & \multicolumn{2}{|c|}{ Two-stage (\%) } & \multicolumn{2}{|c|}{ One-stage (\%) } & \\
\hline & $\begin{array}{l}\text { No. of } \\
\text { patients }\end{array}$ & Age at surgery & $\begin{array}{l}\text { No. of } \\
\text { patients }\end{array}$ & $\begin{array}{l}\text { Age at } \\
\text { surgery }\end{array}$ & \\
\hline Veau I & - & & $11(100 \%)$ & SHP: 1y 7mo & $\mathrm{n} 1=11$ \\
\hline Veau II & $14(70 \%)$ & $\begin{array}{l}\text { SP: } 1 \text { y } 2 \mathrm{mo} \\
\text { HP: } 2 \text { y } 2 \mathrm{mo}\end{array}$ & $6(30 \%)$ & SHP: 3y 9mo & $\mathrm{n} 2=20$ \\
\hline Veau III & 27 (82\%) & $\begin{array}{l}\text { SP: } 1 \text { y } 9 \mathrm{mo} \\
\text { HP: } 4 y=6 m o\end{array}$ & $6(18 \%)$ & SHP: 2y 2mo & $n 3=33$ \\
\hline Veau IV & $12(75 \%)$ & $\begin{array}{c}\text { SP: 1y } 10 \mathrm{mo} \\
\text { HP: } 4 y\end{array}$ & $4(25 \%)$ & SHP: 2y $4 \mathrm{mo}$ & $\mathrm{n} 4=16$ \\
\hline Total & $53(66 \%)$ & & 27 (34\%) & & \\
\hline
\end{tabular}

SP - soft palate; HP - hard palate; SHP - soft and hard palate

palate), Veau III (soft and hard palate and unilateral cleft of the lip/primary palate) and Veau IV (soft and hard palate and bilateral cleft of the lip/primary palate) [7].

All patients were admitted to the hospital and the palate repair was performed by a cleft trained surgeon under general anesthesia. The techniques used are described in the Results section of this paper. Patients were followed- up postoperatively in order to check for oronasal fistula occurrence.

The effectiveness of the treatment was assessed considering the closure of the palatal defect, absence of bleeding or infection immediately postoperative and of any dehiscence (oronasal fistula).

\section{Results}

In the last 5 years, 80 children with cleft palate (with or without cleft lip) received cleft palate repair by our cleft team. Twenty-three of the patients were girls (29\%), while 57 were boys $(71 \%)$.

As seen in Table I, 31 patients (38.75\%) presented isolated cleft palate, while 49 patients $(61.25 \%)$ presented cleft lip and palate. In the isolated cleft palate group, there

Table III. Relation between cleft type, cleft palate closure and fistula incidence

\begin{tabular}{|c|c|c|c|c|c|c|}
\hline \multirow[t]{2}{*}{ Cleft type } & \multicolumn{2}{|c|}{ Two-stage (\%) } & \multicolumn{2}{|c|}{ One-stage (\%) } & \multicolumn{2}{|c|}{ Total $n=74$} \\
\hline & $\begin{array}{c}\text { No. of } \\
\text { patients }\end{array}$ & $\begin{array}{l}\text { No. of pa- } \\
\text { tients with } \\
\text { fistulae }\end{array}$ & $\begin{array}{c}\text { No. of } \\
\text { patients }\end{array}$ & $\begin{array}{l}\text { No. of pa- } \\
\text { tients with } \\
\text { fistulae }\end{array}$ & & \\
\hline Veau I & - & & 11 & 0 & $\mathrm{n} 1^{\prime}=11$ & 0 \\
\hline Veau II & 13 & 6 & 6 & 1 & $\mathrm{n} 2^{\prime}=19$ & 7 \\
\hline Veau III & 23 & 7 & 6 & 0 & $n 3^{\prime}=29$ & 7 \\
\hline Veau IV & 11 & 3 & 4 & 1 & $\mathrm{n} 4^{\prime}=15$ & 4 \\
\hline Total & 47 & 16 & 27 & 2 & 74 & 18 \\
\hline Fistula rate & \multicolumn{2}{|c|}{$34 \%$} & \multicolumn{2}{|c|}{$7.4 \%$} & \multicolumn{2}{|c|}{$24.3 \%$} \\
\hline
\end{tabular}

was a slight predominance of females (17 patients, 55\%), while in the cleft lip and palate group there was an overwhelming male presence (43 patients, 87.75\%).

Cleft type according to Veau classification identified n1 $=11$ children with cleft of the soft palate only (Veau I), n2 $=20$ children with cleft of the soft and hard palate (Veau II), n3 = 33 patients presenting unilateral cleft lip and palate (Veau III) and $\mathrm{n} 4=16$ of them having bilateral cleft lip and palate (Veau IV) (Table I).

The retrospective analysis referring to the protocol used with information about the number of stages of palate closure (one- or two-stage) and the age of children when operated, according with Veau classification, is summarized in Table II. Sixty-six percent of them underwent two-stage closure, while $34 \%$ one-stage closure.

The age at the time of surgery varied with cleft type and the protocol used (one- or two-stage closure). In Veau I, all 11 patients (100\%) had one-stage procedure, obviously, using the intravelar veloplasty. In the majority of cases, the average age at the time of surgical repair was 1 year and 2 months. There were 2 children with asymptomatic bifid uvula, who presented later for surgical repair, at 15 and 17 years, respectively.

Out of the 20 patients with Veau II, 70\% of cases (n $=14$ ), treated in the first four years of the study (20082011) underwent a two-stage closure, while $30 \%$ of cases $(n=6)$ were repaired in one-stage in 2012, using the von Langenbeck technique along with Furlow Z-plasty. Average age for each stage considering the specific Veau class is presented in Table II.

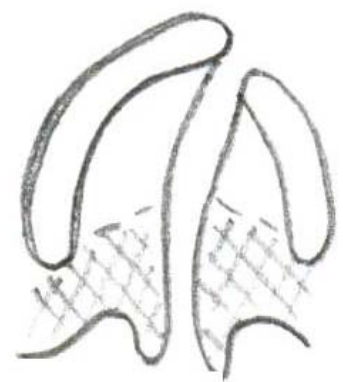

III

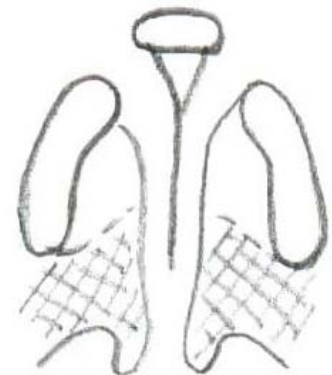

IV

Fig. 1. Veau classification for cleft palate: Veau I - soft cleft palate, Veau II - hard and soft cleft palate, Veau III - hard and soft cleft palate and unilateral cleft lip, Veau IV - hard and soft cleft palate and bilateral cleft lip. 


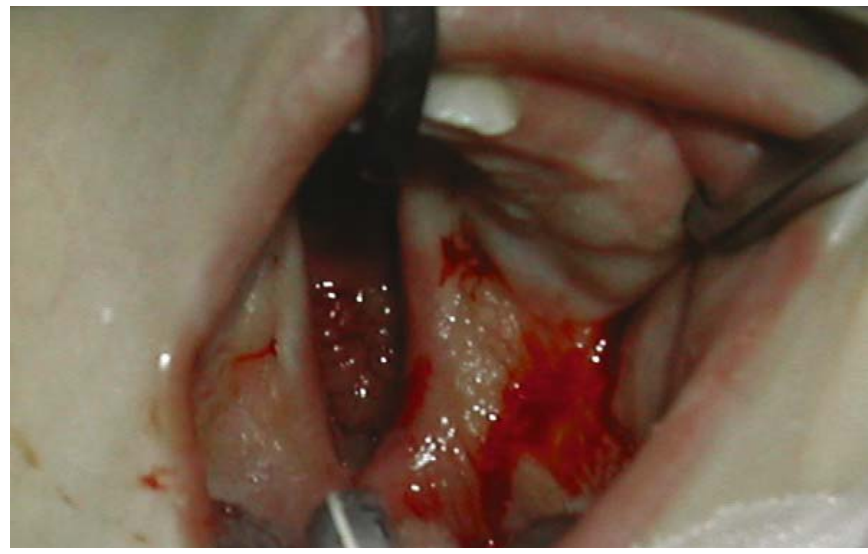

Fig. 2. A unilateral cleft lip and palate (Veau III) boy after lip repair. Complete cleft palate before palate surgery. A two-stage closure will be done.

Thirty-three patients associated cleft palate to unilateral cleft lip, belonging to the Veau III class. Out of them, 18 cases were left sided, and 15 cases right sided. Eighty-two percent of the Veau III cases $(\mathrm{n}=27)$ received a two-stage procedure, while $18 \%$ of cases $(n=6)$ one-stage closure.

Out of the 6 patients closed in one stage, 1 had only soft palate, and soft palatoplasty was performed, while the other 5 cases had cleft soft and hard palate but incomplete primary palate, being treated with von Langenbeck palatoplasty and Furlow procedure, also in one stage.

As mentioned, in class Veau IV we found 16 patients treated for primary cleft palate closure during the study period. Seventy-five percent of them $(n=12)$ had a two-stage procedure, while $25 \%(\mathrm{n}=4)$ a one-stage closure. Average age for each type of closure is presented in Table II. There was one child with the soft palate repair done at 3 years and he didn't present for surgery until the age of 11 years, when the hard palate was repaired. Another neglected case was a patient operated for cleft lip on time and who presented for palate repair at the age of 18 years. Out of the 4 patients closed in one stage, 2 had only soft palate and soft palatoplasty was performed, while in the cases of other 2 , the older age made us choose the one-stage protocol, with Bardach two flap palatoplasty.

All patients in classes Veau II, III and IV who underwent the two-stage repair, had the soft palate repair using

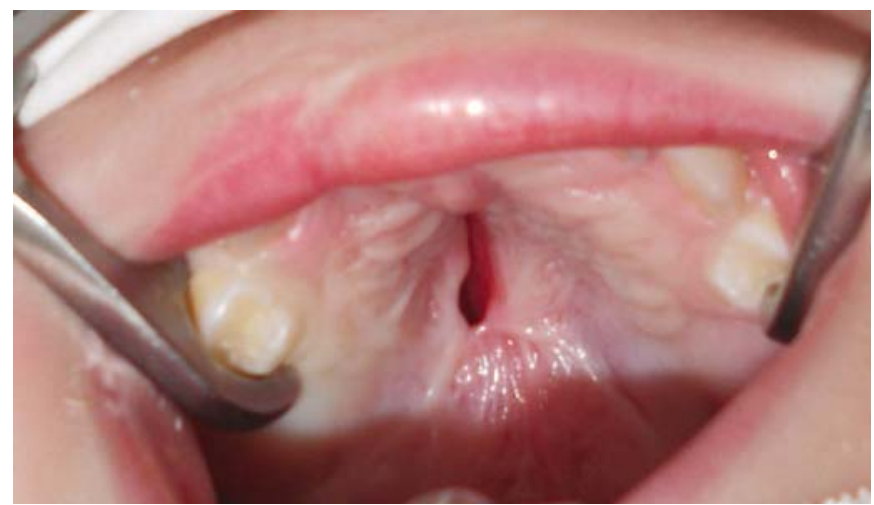

Fig. 4. Same case 1 year later. Soft palate repaired. Residual cleft of the hard palate.

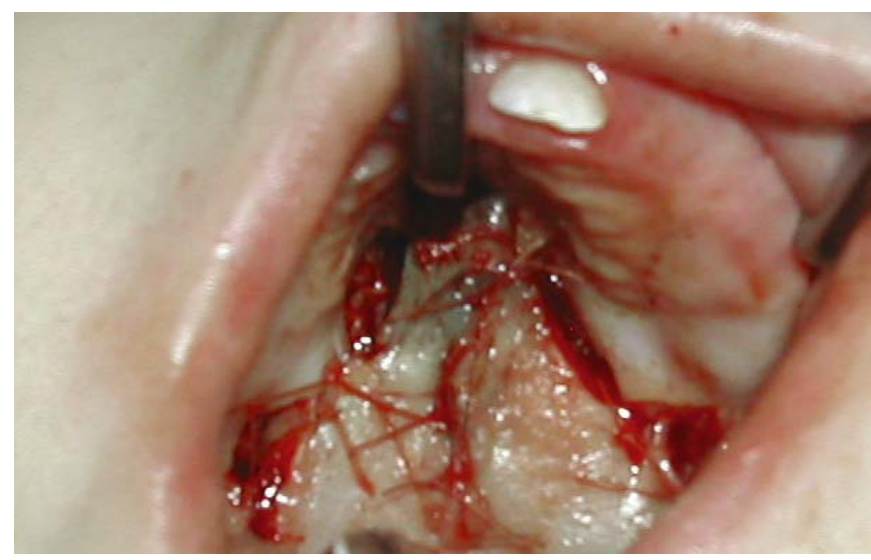

Fig. 3. Same case immediately after soft palate repair, 1 year and 3 months old.

zig-zag incisions at the junction between the soft and hard palate and raising 2 miomucosal flaps from the soft palate, each from one side, sutured together in the midline [6]; the hard palate was closed using an eversed mucoperiosteal flap from the hard palate [6].

The incidence of the oronasal fistulas was calculated according to Veau classification and stages of the surgical palate closure (one-stage or two-stage), as seen in Table III.

Out of the 80 children included in the study, 6 patients (1 Veau II, 4 Veau III, 1 Veau IV) did not finish the twostage palate closure, and were excluded when fistula rate was assessed. The one-stage closure group remained unchanged. Therefore, the results regarding fistula formation are the following: no fistulae in Veau I group, 7 fistulae in Veau II class (6 in two-stage closure), 7 fistulae in Veau III class (all in two-stage protocol) and 4 fistulae in Veau IV cleft ( 3 in the two-stage repair). Fistulae occurred in a total of 18 patients, and thus the overall rate of cleft repairs complicated by fistulae was $24 \%$ (18 out of 74 patients). More fistulae were found in the two-stage group (16 out of 47 patients) than in the one-stage group ( 2 out of 27 patients), with a rate of $34 \%$ compared to a rate of $7.4 \%$.

\section{Discussion}

Among the cleft population, in the literature, the most common diagnosis is cleft lip and palate (CLP) in almost

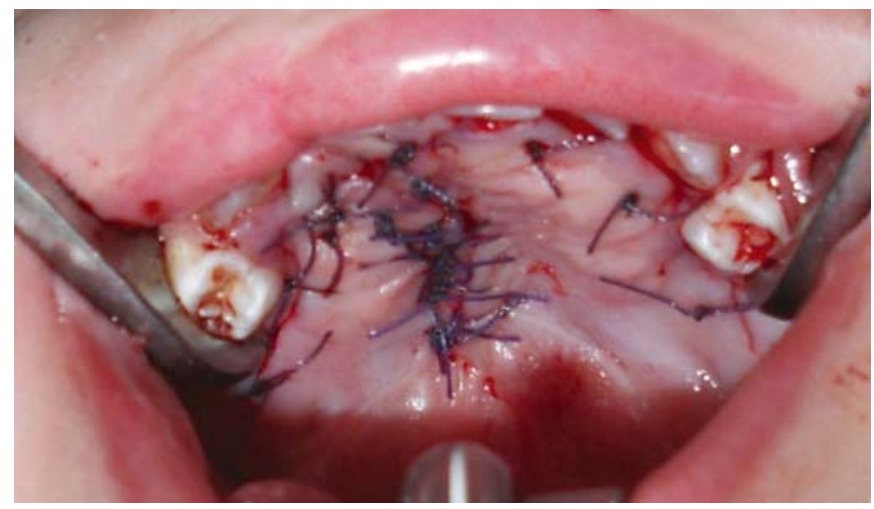

Fig. 5. Same case immediately after hard palate repair, 2 years and 4 months old. 
half of the cases (46\%), followed by isolated cleft palate $(\mathrm{CP})$ at one third of cleft population (33\%), and then isolated cleft lip (CL) at $21 \%[8,9]$. The study population in this paper comprises 49 patients with CLP (representing $61 \%)$ and 31 patients with isolated CP (39\%); children with isolated CL were excluded.

As mentioned, the age at the time of surgery varied according with cleft type and the protocol used. In Veau I (cleft of the soft palate only), palate repair is done in onestage procedure, the recommended age for surgery being 6 to12 months. Our patients were operated at the recommended age, or if not, at the age they presented to the hospital, sometimes late, when a speech problem diagnosed a cleft palate. Patients with asymptomatic bifid uvula usually present later, whereas those with submucous cleft were presented often with velopharyngeal insufficiency $[2,8]$.

In Veau II, Veau III and Veau IV (complete cleft of the soft and hard palate with or without cleft lip), palate repair can be performed in one- or two-stage closure. Onestage procedure is recommended to be done at 1-2 years of age, or anytime after, if the patients present late [10]. Techniques used for Veau II are von Langenbeck or VeauWardill-Kilner, while operative technique for Veau III and Veau IV is Bardach two-flap palatoplasty $[11,12]$. The twostage closure recommends closing soft palate at around 1 year, while hard palate is repaired at $2 \frac{1 / 2-3}{\text { years of age. The }}$ age when closing the hard palate was 8 years when the protocol was first described by Schweckendiek, but later studies proved that normal maxillary growth is not impaired when lowering the age towards 3 years.

Results of the retrospective analysis regarding the average age at surgery were, more or less, in accordance with the recommended age in international protocols presented before; we found situations when this age was higher, in neglected cases. Sometimes the patients would present to hospital at an older age, or they would start staged surgery (lip repair, soft palate closure) and would not finish the protocol. Age at (first) surgery was higher with the one-stage closure (Table II), because in children who presented late to palate surgery there was no reason to choose the two-stage closure.

The reported fistula rates in the literature range from $0 \%$ to $58 \%$ for two-stage repair and from $0 \%$ to $40 \%$ for one-stage repair $[7,13]$. We found a fistula incidence of $34 \%$ in patients with two-stage repair; whereas, only $7.4 \%$ of patients with one-stage repair had fistula. The overall fistula incidence found was $24 \%$.

Our main goal was to compare the risk of oronasal fistula formation in the two-stage palatal closure recently introduced in our department, with the classic one-stage protocol. The relatively small samples of each type of cleft and also a variety of technical surgery used in either of the two protocols represent limits of this study. In the literature, for the cleft type, some authors consider fistula incidence is proportional with the severity of the malformation $[14,15]$, while others don't [7]. Better than the cleft type seems to be, for fistula prediction, the width of the cleft palate $[7,16]$.

\section{Conclusions}

Due to the Eurocleft recommendation, our cleft palate team used for over a decade the two-stage protocol for cleft palate primary repair. This protocol brought some advantages compared with the one-stage classical approach: it is a safer procedure (in terms of pedicle injuries risk) and provides good maxillary growth. But the significantly higher incidence of fistulae, the necessity for two operations under general anesthesia, sometimes with abandon of the second one, determine us to consider the one-stage procedure in specific cases. In the last year, we have used one-stage palate repair for all Veau II cases and some narrow Veau III and IV cases; neglected cases, presenting for surgery at an older age also should be done using the one-stage procedure. Nevertheless, the two-stage closure remains the procedure of choice for all wide Veau III and Veau IV cases.

\section{References}

1. Salyer KE, Sng KW, Sperry E. Two-Flap Palatoplasty: 20-Year Experience and Evolution of Surgical Technique, Plast Reconstr Surg. 2006;118(1): 193-203.

2. Van Aalst JA, Kumar Kolappa K, Sadove M. Nonsyndromic Cleft Palate, Plast Reconstr Surg. 2008;121(1):1-13.

3. Khosla RK, Mabry K, Castiglione CL. Clinical Outcomes of the Furlow Z-Plasty for Primary Cleft Palate Repair, Cleft Palate Craniofac J. 2008;45(5):501-509.

4. Schweckendiek W, Doz P. Primary veloplasty: long-term results without maxillary deformity, a twenty-five year report. Cleft Palate J. 1978;15:268274

5. Semb G, Brattstrom V, Molsted K, Prahl-Andersen B, Shaw W. The Eurocleft Study: Intercenter Study of Treatment Outcome in Patients with Complete Cleft Lip and Palate. Part 1: Introduction and Treatment Experience, Cleft-Palate Craniofac J. 2005;42(1):64-68.

6. Lilja J, Friede H, Johanson B. Changing Philosophy of Surgery of the Cleft Lip and Palate in Goteborg, Sweden. In Berkowitz S. (ed): Cleft Lip and Palate Perspectives in Management, Volume II: An Introduction to Craniofacial Anomalies, Singular Publishing Group, San Diego, 1996, 155-169.

7. Landheer JA, Breugem CC, Mink van der Molen AB. Fistula Incidence and Predictors of Fistula Occurence After Cleft Palate Repair: Two-stage Closure Versus One-Stage Closure, Cleft Palate Craniofac J. 2010;47(6): 632-630.

8. Hopper RA, Cutting C, Grayson B. Cleft lip and Palate. In Thorne CB, Bartlett SP, Beasley RW et al (eds.): Grabb and Smith's Plastic Surgery, Sixth edition, Lippincott Williams \& Wilkins, Philadelphia, 2007, 201-225.

9. Hoffman WY, Mount DL. Cleft Palate Repair. In Mathes SJ, Hentz VR. (eds.): Plastic Surgery, 2nd Edition, Volume IV: Pediatric Plastic Surgery, Saunders-Elsevier, Philadelphia, 2006, 249-266.

10. Katzel EB, Basile P, Koltz PF, Marcus JR, Girotto JA. Current Surgical Practices in Cleft Care: Cleft Palate Repair Techniques and Postoperative Care, Plast Reconstr Surg. 2009;124(3):899-905.

11. Schnitt DE, Agir H, David DJ. From Birth to Maturity: A Group of Patients Who Have Completed Their Protocol Management. Part I. Unilateral Cleft Lip and Palate. Plast Reconstr Surg. 2004;113(3):805-817.

12. David DJ, Anderson PJ, Schnitt DE, Nugent MAC, Sells R. From Birth to Maturity: A Group of Patients Who Have Completed Their Protocol Management. Part II. Isolated Cleft Palate Plast Reconstr Surg. 2006;117(2):515-525.

13. Losee JE, Smith DM, Afifi AM, Jiang S, Ford M, Vecchione L, Cooper GM, Naran S, Mooney MP, Serletti JM. A Successful Algorithm for Limiting Postoperative Fistulae following Palatal Procedures in the Patient with Orofacial Clefting, Plast Reconstr Surg. 2008;122(2):544-553.

14. Cohen SR, Kalinowski J, LaRossa D, Randall P. Cleft Palate Fistulas: a Multivariate Statistical Analysis of Prevalence, Etiology and Surgical Management. Plast Reconstr Surg. 1991;87(6):1041-1047.

15. Muzaffar AR, Byrd HS, Rohrich RJ, Johns DF, LeBlanc D, Beran SJ et al. Incidence of Cleft Palate Fistula: an Institutional Experience with Twostage Palatal Repair. Plast Reconstr Surg. 2001;108(6):1515-1518.

16. Parwaz MA, Sharma RK, Parashar A, Nanda V, Biswas G, Makkar S. Width of Cleft Palate and Postoperative Palatal Fistula-do they correlate? J Plast Reconstr Aesthet Surg. 2009;62(12):1559-1563. 